\title{
Leading teams during simulated pediatric emergencies: a pilot study
}

This article was published in the following Dove Press journal:

Advances in Medical Education and Practice

6 January 2015

Number of times this article has been viewed

\author{
Ester H Coolen' \\ Jos M Draaisma ${ }^{2}$ \\ Sabien den Hamer ${ }^{3}$ \\ Jan L Loeffen ${ }^{2}$ \\ 'Department of Pediatric Surgery, \\ Amalia Children's Hospital, \\ Radboud University Medical Center, \\ ${ }^{2}$ Department of Pediatrics, Amalia \\ Children's Hospital, Radboud \\ University Medical Center, \\ ${ }^{3}$ Department of Communication \\ Science, Radboud University, \\ Nijmegen, the Netherlands
}

Purpose: Leadership has been identified as a key variable for the functioning of teams and as one of the main reasons for success or failure of team-based work systems. Pediatricians often function as team leaders in the resuscitation of a critically ill child. However, pediatric residents often report having little opportunity to perform in the role of team leader during residency. In order to gain more insight into leadership skills and behaviors, we classified leadership styles of pediatric residents during simulated emergencies.

Methods: We conducted a prospective quantitative study to investigate leadership styles used by pediatric residents during simulated emergencies with clinical deterioration of a child at a pediatric ward. Using videotaped scenarios of 48 simulated critical events among 12 residents, we were able to classify verbal and nonverbal communication into different leadership styles according to the situational leadership theory.

Results: The coaching style (mean $54.5 \%$, SD 7.8 ) is the most frequently applied by residents, followed by the directing style (mean $35.6 \%$, SD 4.1 ). This pattern conforms to the task- and role-related requirements in our scenarios and it also conforms to the concept of situational leadership. We did not find any significant differences in leadership style according to the postgraduate year or scenario content.

Conclusion: The model used in this pilot study helps us to gain a better understanding of the development of effective leadership behavior and supports the applicability of situational leadership theory in training leadership skills during residency.

Keywords: leadership, residency, medical education, simulation, emergencies

\section{Introduction}

Leadership has been identified as a key competence for the functioning of teams and as one of the main reasons for success or failure of team-based work systems. ${ }^{1}$ Development of leadership is important in clinical medicine, as the interaction of the leader with supporting members of the team is critical to both quality and safety of patient care, as well as the establishment of a shared mental model and education of the team members. ${ }^{2}$ Teams that function with an effective team leader adhere more closely to established protocols, sustain fewer medical errors, and, as a result, have favorable outcomes for their patients, both simulated and real. ${ }^{3}$ Therefore, leadership skills of medical professionals should be trained in the early stages of their career. Investing in the leadership growth of a physician early on might allow him or her to acquire the necessary skills to function as a collaborative leader, optimizing team performance. ${ }^{4}$

General pediatricians often function as team leaders during the treatment of critically ill children. Simulated emergencies are an excellent opportunity for medical
Correspondence: Ester H Coolen Department of Pediatric Surgery, Radboud University Medical Center, PO Box 9I0I, NL-6500 HB Nijmegen (6I8), the Netherlands Email ester.coolen@radboudumc.nl (c) (1) () 2015 Coolen et al. This work is published by Dove Medical Press Limited, and licensed under Creative Commons Attribution - Non Commercial (unported, v3.0) BY LC License. The full terms of the License are available at http://creativecommons.org/licenses/by-nd/3.0/. Non-commercial uses of the work are permitted without any further permission how to request permission may be found at: http://www.dovepress.com/permissions.php 
professionals to increase awareness of the influence of leadership skills in critical situations and practice leadership skills, without endangering patient safety. However, residential training often does not contain a structured teaching program or assessment of leadership skills, despite the known importance of effective leadership and team communication to patient outcomes. Studies to assess leadership behavior during pediatric emergencies are limited and can be very challenging because of changes in team composition, patient acuity, and lack of a gold standard for effective leadership. Even under standardized conditions, as is the case during simulated events, checklists scoring of leadership skills is often not specific enough to provide proper feedback and is only a basic outline for wanted leadership behavior, without taking into account evolving priorities and changing circumstances during clinical practice. A concept of effective leadership behavior that does take into account transitions in patient acuity and clinical context is the situational leadership theory (SLT) developed by Hersey et al. This theory suggests that effective leaders change their leadership styles based on the experience of the team members and (changing) complexity of the medical situation., ${ }^{5,6}$ Instead of using just one style, leaders should be able to change and adapt their leadership style depending on the level of understanding and experience of the team, as well as on other factors, such as a clinical deterioration of the patient. ${ }^{5,6}$ Hersey et al distinguish four main leadership styles, each with a distinct set of related behavior ${ }^{5}$ :

- Delegating style - Leaders pass most of the responsibility onto the follower or group. The leaders still monitor progress, but they are less involved in decisions.

- Supporting style - Leaders focus more on the relationship and less on direction. The leader works with the team and shares decision-making responsibilities.

- Coaching style - Leaders still provide information and direction, but there is more communication with followers. Leaders "sell" their message to get the team on board.

- Directive style - Leaders tell their people exactly what to do, and how to do it.

The directive and delegating style focus on task behavior, while the coaching and supporting style aim at relation behavior. Task behavior means that the leader is oriented toward the necessary tasks. He or she organizes and defines the roles of the group and explains what activities are to be undertaken. Relationship behavior means that the leader focuses on a good relationship with his or her team members. This is achieved by communicating, providing emotional support, and offering facilitating behavior. Apparently, there is no superior form of leadership. Leaders have to match their style to their own requirements and the context of the situation, which is called "situational leadership". ${ }^{3}$ The concept of situational leadership is well established in acute care settings such as resuscitations in the emergency room or an intensive care unit (ICU). However, the assessment of leadership styles during sudden transitions in clinical condition, as is more often the case in a pediatric ward, is not as well understood. In order to test the applicability of SLT during simulated pediatric critical care, we conducted a prospective quantitative study to investigate the leadership behavior and the corresponding leadership styles used by pediatric residents during a simulated emergency with clinical deterioration of a child at the pediatric ward. To put our findings into context and assess the educational needs of our residents, all affiliated pediatric residents were given a digital survey asking about their leadership experiences and preferred leadership styles during different clinical situations.

\section{Materials and methods Participants}

The study group consisted of pediatric residents (postgraduate year [PGY] 1-5) and pediatric consultants in the first year after graduation (defined as PGY 6). A total of 28 pediatric residents were trained multiple times (range 2-6) at our skills and simulation laboratory and at different time intervals depending on their PGY and hospital placement, during a 1-year study period. We were able to include twelve pediatric residents who participated in four different scenarios after obtaining informed consent. The scenarios they participated in were randomly chosen out of six different pediatric critical-care situations that pediatricians should be able to master according to our residential training program. Subjects were told that the video recordings of the simulated events would be saved and reviewed by the researchers. The subjects had no information regarding the objectives of the study (assessing leadership styles) to limit bias of our results. Forty-eight videos of simulated pediatric events, which included those in which residents played the role of the team leader, were collected and analyzed on leadership styles according to the SLT developed by Hersey et al (Table 1). ${ }^{5,7}$ Nurses and pediatric consultants who played a nonscripted role in the scenarios as part of the team gave written consent to analyze the selected videos.

\section{Setting}

The study was conducted in the Skills and Simulation Unit of our center, which is equipped with cameras and microphones. Scenarios took place using a high-fidelity patient simulator $\left(\right.$ METI Pediasim $\left.{ }^{\circ}\right)$. We used scripted scenarios with a dura- 
Table I Leadership behavior related to different leadership styles of situational leadership theory according to Hersey et al ${ }^{6}$

\begin{tabular}{ll}
\hline Supporting & Coaching \\
- Is focused on coworkers, invests in relationships & - Actively tries to diminish hierarchical differences between leader and coworkers \\
- Actively rewards and compliments coworkers & - Stimulates involvement of coworkers \\
- Wants coworkers to excel in their work & - Invests in commitment of all coworkers \\
- Is reluctant to take initiative & - Stimulates entire team to contribute to decision making \\
- Does not lean on hierarchical structures & - Invites coworkers to participate in discussion \\
- Is passive and reactive rather than proactive & - Will not recede from conflicts \\
- Creates possibilities for innovation and coworker initiative & - Invests in two-way communication \\
- Actively coaches coworkers & \\
- Simulates collaboration between coworkers & Directive \\
Delegating & - Is dominant with high level of confidence \\
- Is not focused on task execution & - Is focused on task execution \\
- Is not focused on relation with coworkers & - Is proactive, and controlling \\
- Transfers responsibilities to coworkers & - Is goal oriented \\
- Monitors general procedures & - Takes initiative, is dynamic and ambitious \\
- Does not focus on detail & - Is engaged with the patient \\
- Keeps distant from coworkers & - Is cost-conscious \\
- Is reluctant to change & \\
- Is not open for ideas of coworkers & \\
- Functions as a hatch for facts and figures &
\end{tabular}

Note: Data from Hersey et al. ${ }^{6}$

tion of approximately 15 minutes per session. The performing team consisted of two pediatric nurses, a pediatric resident, and a pediatric consultant. We used six different scenarios in which the children deteriorated clinically and entered a critical clinical situation. The scenario algorithms had a similar level of complexity as in the national training program for pediatric residents (acute asthma, hypovolemic shock, sepsis, anaphylaxis, hypoglycemia, and pleural empyema). The scenarios were written by training experts who are advanced pediatric life support (APLS) instructors and crew resource management trainers according to EUSIM guidelines and pediatricians involved in acute care for children at our center.

\section{Procedure}

Pediatric residents $(n=12$, three men/nine women) participated in four different simulations and were grouped according to their level of training (PGY 1-6). To assess leadership style, the video recordings of each scenario were divided into short clips. All verbal and nonverbal communications during these fragments were identified and made verbatim as behavioral units (short description of behavior) by a communications scientist ( $\mathrm{SH})$. These behavioral units were then classified into leadership behavior styles according to SLT of Hersey et al (Table 1). The percentage of behavior related to a specific leadership style (supporting, coaching, delegating, and directive leadership) was computed from the data to evaluate leadership styles in relation to the year group (PGY) and scenario content. We used a chi-squared test with leadership style as a dependent variable and PGY as an independent variable to determine significant differences in leadership behavior between year groups. The same was done for scenario content, using a chi-squared test with leadership style as dependent variable and scenario type as independent variable to detect differences in leadership behavior due to scenario content. Results were compiled for statistical analysis using SPPS 17.0. To determine the inter-rater reliability of our classification system, behavioral units were classified by a second independent researcher and pediatrician (EC). Both raters participated in a training session and a consensus conference to become familiar with the four leadership styles based on verified descriptions of each leadership style. A weighted $\kappa$-coefficient was computed.

\section{Digital survey on preferred leadership styles}

To assess the specific needs in leadership training as felt by the residents, the residents affiliated with our university hospital $(n=38)$ were given a digital survey, in which they were asked about preferred leadership styles in acute situations and daily routine. Residents were shown 32 behaviors according to the SLT list (Table 1) in random order and asked whether these behaviors were the preferred behaviors during a resuscitation event and whether these were applicable to their own behavior as team leader. The same was done for behavior during routine clinical team work. A 5-point Likert scale was used ( $1=$ not applicable to preferred style of leadership; $5=$ totally applicable to preferred style of leadership). We also collected 
relevant background information, such as the level of training; when they had last taken any advanced life-support course such as the European pediatric life support (EPLS), APLS, or Neonatal life support (NLS); and their experience in working on ICUs (neonatal ICU or pediatric ICU).

\section{Results}

\section{Profile of leadership styles applied during resuscitations}

Twelve pediatric residents participated in 48 team simulations of a pediatric critical-care event. The scenario duration was from 10.51 to 16.31 minutes, with a mean duration of 13.53 minutes. From the video recordings, 2,648 behavioral units were identified and classified into one of the leadership styles described in Table 1. There was a high level of inter-rater reliability between the two raters (weighted kappa $r=0.867$ ). The coaching style is the most frequently applied style (mean $54.5 \%$, SD 7.8), followed by the directing style (mean $35.6 \%$, SD 4.1). The delegating and supporting styles are used to a much smaller extent, 4.4\% (SD 2.9) and 5.5\% (SD 4.1), respectively, during a simulated resuscitation (Figure 1).

\section{Profile of leadership styles in relation to Postgraduate Year}

In general, leadership styles are uniformly distributed over the PGYs. No significant differences between year groups could be extracted from our data using a chi-squared test $\left(\chi^{2}=29.025 ; d f=15 ; P=0.016\right)$. All residents showed the same leadership behavior pattern, with the highest percentage of coaching behavior (coaching style) followed by directing behavior (directive style). The delegating and supporting leadership style were hardly applied (Figure 2).

\section{Profile of leadership in relation to scenario content}

All residents performed in scripted scenarios involving critically ill children. Considering that the scenario content is slightly different and leadership style is linked to level of task complexity and acuity, we analyzed leadership style for each individual scenario (Table 2). No significant differences in preferred leadership style were found $\left(\chi^{2}=37.717 ; d f=30\right.$; $P=0.157)$.

\section{Results of preferred leadership style questionnaire}

The results of the preferred situational leadership style questionnaire are shown in Table 3. Thirty-one residents completed our questionnaire (81.6\%). Two types of behaviors were most applicable to their leadership style according to residents: "stimulates involvement of coworkers" and "invests in two-way communication". Both behaviors apply to the coaching style observed most during the scenarios. Behaviors

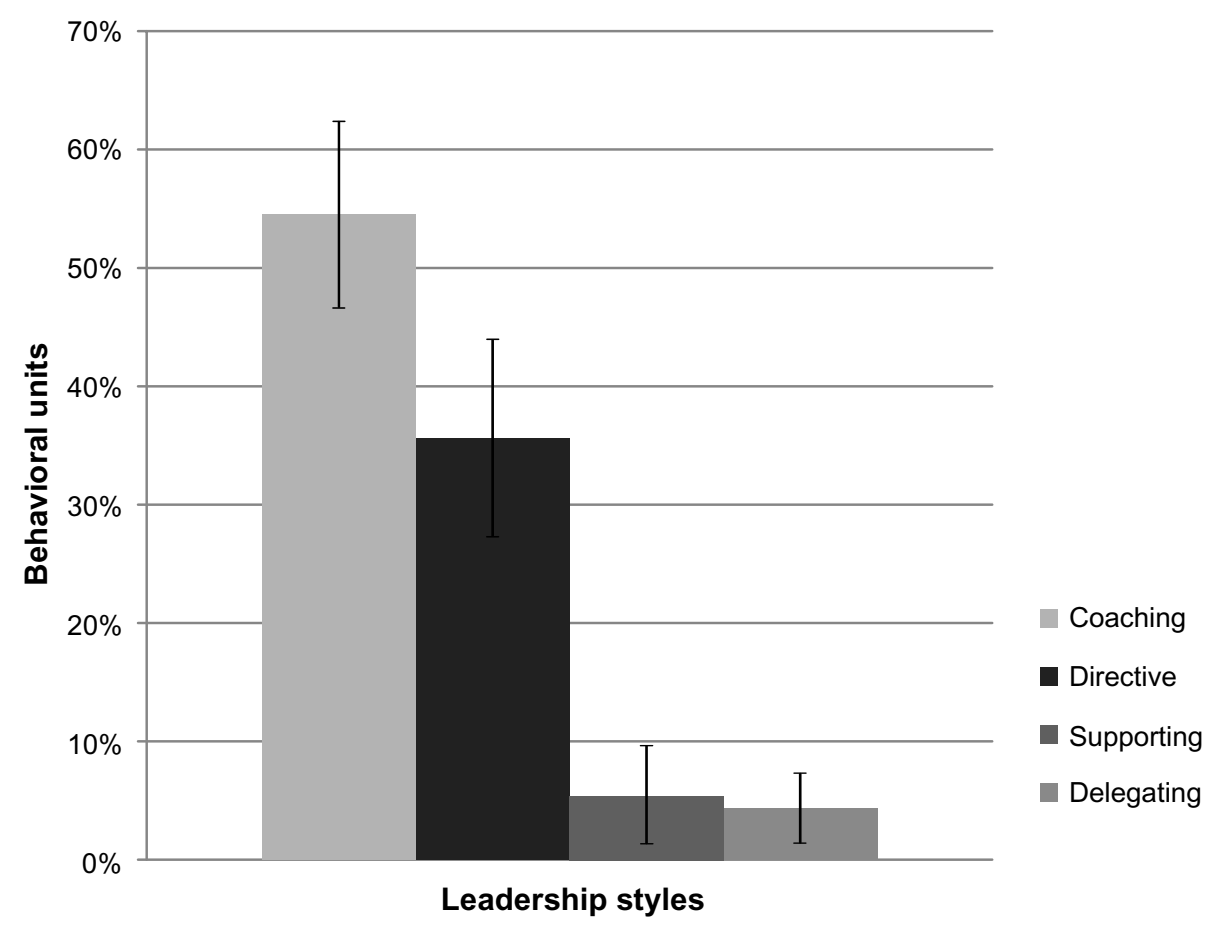

Figure I Percentage of behavioral units per leadership style. 


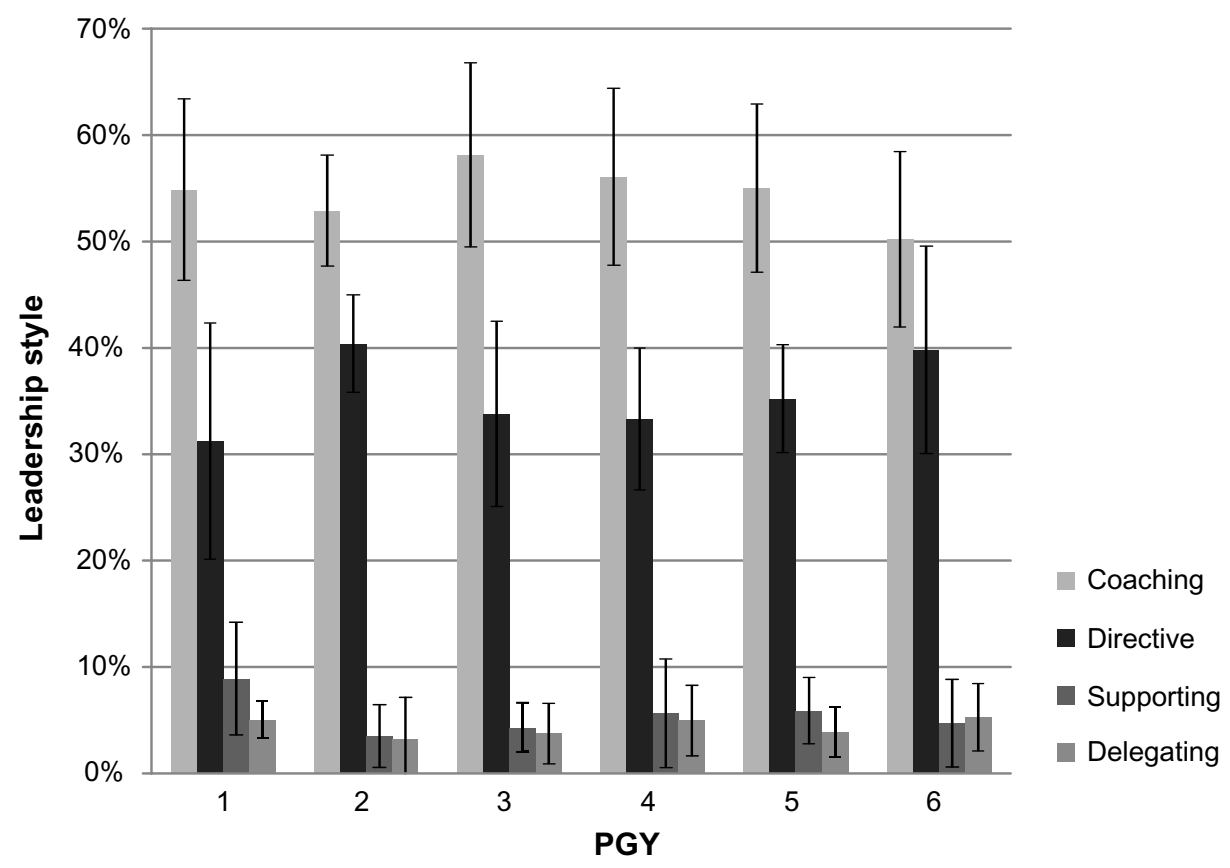

Figure 2 Leadership style in relation to PGY.

Notes: $\chi^{2}=37.717 ; d f=30 ; P=0.157$.

Abbreviation: PGY, postgraduate year.

least applicable to their leadership style were "keeps distant from coworkers" and "is not focused on relation with coworkers". Both behaviors apply to the delegating style that was least observed during the scenarios. In general, the data showed a distinct preference for task-related leadership styles during critical events. For daily routine leadership, residents showed a preference for a supporting leadership style (30.3\% of behaviors), with the most important behavior being "simulates collaboration between coworkers".

Advanced life-support training (EPLS/APLS/NLS) and clinical experience in an ICU did not make a distinct difference in their perception of leadership. The only exception was that residents with recent pediatric intensive care unit experience chose more often for leadership behavior of the delegating style as being fit for a resuscitation situation like: "monitors general procedures" and "transfers responsibilities to coworkers".

\section{Discussion}

Developing leadership skills in residents is important, as the effectiveness of leadership is critical to timely and safe patient care as well as for the education of team members. However, there is no gold standard for effective leadership behavior or criteria that should be met for optimal leadership and can be generalized to any given situation. This makes teaching leadership skills to residents a very complex and difficult endeavor.

Our data support the concept of SLT during simulated pediatric emergencies, not only as a theoretical concept but also as a tool to classify leadership behavior of residents into different leadership styles. In our setting, using a range of scenarios with similar patient acuity, all PGYs show a very similar leadership behavior pattern. Residents preferentially chose a directive $(35.6 \%)$ or coaching style $(54.5 \%)$ that would lead their team during a simulated critical event. This pattern conforms to the task- and role-related requirements in our scenarios,

Table $\mathbf{2}$ Leadership style in relation to scenario content

\begin{tabular}{llllll}
\hline Scenario & \multicolumn{2}{l}{ Leadership style } & & & Total \\
\cline { 2 - 5 } & Coaching & Directive & Supporting & Delegating \\
\hline Anaphylaxis & $136(54.6 \%)$ & $77(30.9 \%)$ & $18(7.2 \%)$ & $18(7.2 \%)$ & $249(100 \%)$ \\
Acute asthma & $100(52.9 \%)$ & $71(37.6 \%)$ & $10(5.3 \%)$ & $8(4.2 \%)$ & $189(100 \%)$ \\
Hypoglycemia & $239(49.5 \%)$ & $206(42.7 \%)$ & $24(5.0 \%)$ & $14(2.9 \%)$ & $483(100 \%)$ \\
Hypovolemic shock & $68(57.1 \%)$ & $32(26.9 \%)$ & $11(9.2 \%)$ & $8(6.7 \%)$ & $119(100 \%)$ \\
Pleurempyema & $35(62.5 \%)$ & $17(30.4 \%)$ & $1(1.8 \%)$ & $3(5.4 \%)$ & $56(100 \%)$ \\
Sepsis & $343(55.5 \%)$ & $217(35.1 \%)$ & $30(4.9 \%)$ & $28(4.5 \%)$ & $618(100 \%)$ \\
\hline
\end{tabular}

Notes: $\chi^{2}=37.717 ; \mathrm{df}=30 ; P=0.157$. 
Table 3 Most applicable and least applicable leadership behavior during a critical event and routine practice among pediatric residents according to the situational leadership questionnaire

\begin{tabular}{llllll}
\hline Leadership style & \multicolumn{2}{l}{ Critical event } & & \multicolumn{2}{l}{ Routine clinical practice } \\
\cline { 2 - 3 } \cline { 5 - 6 } & Most applicable & Least applicable & & Most applicable & Least applicable \\
\hline Coaching & $21.2 \%$ & $17.7 \%$ & $42.4 \%$ & $5.4 \%$ \\
Directive & $33.3 \%$ & $6.5 \%$ & $9.1 \%$ & $37.5 \%$ \\
Supporting & $6.1 \%$ & $48.4 \%$ & $30.3 \%$ & $17.9 \%$ \\
Delegating & $39.4 \%$ & $27.4 \%$ & $18.2 \%$ & $39.3 \%$ \\
\hline
\end{tabular}

ie, starting off with a stable clinical situation, followed by a rapid transition to a more critical situation. The high degree of consistency across the resident leadership profiles may likely be explained by the deteriorating critical situation of the simulations, in line with recent findings of Skog et al. ${ }^{8}$ They found that when the patient acuity was low, there was a preference for the delegating style used by internal medicine residents, and when the patient acuity was high this changed to the coaching and directing style. Another explanation could be found in the fact that the unique selection criteria of the pediatric residency program often result in individuals with comparable personality characteristics and leadership styles to be chosen and accepted within the group. This concept is also known as the attraction-similarity-attrition hypothesis, which suggests that individuals with similar personal characteristics are attracted to and accepted by similar organizations, with turnover occurring among those that do not fit well within the group. ${ }^{9,10}$

We did not find any significant differences in leadership style according to PGY. Although the number of residents per year group was limited in this pilot study, our data somewhat contradict research using a short version of the Multifactor Leadership Questionnaire as a means of identifying leadership areas most in need of training among medical residents during surgical residency, showing that surgical residents reported a more assertive and directive leadership style as they gained competence and clinical experience. ${ }^{9}$ We did not make this observation, although there was a slight, nonsignificant tendency toward a more directive leadership style in the PGY 6 group. This might be explained by other research stating that only experience of more than 3 years is positively correlated with effective leadership behavior, implying that only extensive experience makes a difference in actual performance. ${ }^{3,11,12}$ Another explanation might be found in the fact that surgical residents may opt to employ more active leadership techniques as they gain rank due to a more strict hierarchy of authority in surgical training programs, causing them to feel that they need to live up to the role expectations of both the attending surgical staff and other team members. ${ }^{13}$ Personal characteristics, such as being dominant, leaning on hierarchical structures, and being strongly goal driven, could predispose residents for the surgical profession, ${ }^{14,15}$ which strongly relies on task execution and acute management of patients, whereas the specialism of pediatrics might attract residents with personal characteristics that will enable them to coach teams and patients with complex (chronic) problems as is reflected in our results. ${ }^{16}$ This is also reflected by the outcome of our digital survey on preferred leadership styles among pediatric residents, which shows a strong preference for coaching behavior in both emergencies and daily routine. Preferably, leadership skills should be actively coached during residency regardless of the type of specialization and with the focus on appropriate selection of leadership style depending on skills of the leader, the perceived abilities of the team members, and the acuity of the situation. ${ }^{8}$

Resuscitation training (EPLS/APLS/NLS) and clinical experience with critical events in an ICU did not make a distinct difference in residents' perception of leadership. The only exception was that residents with recent pediatric intensive care unit experience chose more often the delegating style leadership behavior as fit for a resuscitation situation. This might be explained by residents adjusting their reported leadership style to the experience of the team members. Because ICU nursing staff is far more experienced in handling acute events than pediatric ward nurses, the residents feel like they are able to transfer more responsibilities to the team members and focus on monitoring general procedures rather than focusing on details.

The relatively small sample size of participants $(n=12)$ during our observational study obviously limits general assumptions to be made about leadership skills during residency. Residents included in our study may represent a sample that shares characteristics that are similar to this specific resident group and hence may limit the degree to which the results can be generalized to residents in other programs. However, the goal of this study was to get a more objective perspective on leadership during critical events by observing actual behavior in relationship to leadership style and gather information on the residents' perceptions on effective leadership, rather than classifying behavior in to good or bad leadership. Another limitation is the fact 
that we observed leadership behavior in a simulated setting. We did not evaluate the residents' performance during reallife resuscitation to determine whether the learning that occurred translated into better performance during reallife resuscitation. This is very difficult to do because the resuscitation of children is a rare and unpredictable event and comes with a nonstandardized set of conditions with regard to patient acuity and team formation. With respect to the strong preference for the observed direct and coaching leadership styles, we need to mention that for observers it is far more difficult to notice and score nonactive or absent behavior than it is to notice active behavior, such as coaching or giving specific instructions to team members. In this way, we might have underestimated the frequency of delegating or supporting behavior.

However, the elaborate work of classifying behavioral units into different leadership profiles provides us with more insight into the leadership styles of our residents and their preconception about leadership. It underlines the homogeneity of the group in their use of a "coaching style" to lead their team during a critical event. Application of the SLT model can be used to classify leadership behavior during simulated events and may help to identify the best style of leadership in response to the patient's condition, competence of team members, and evolving priorities, rather than teaching residents a fixed set of leadership behavior that applies to every possible circumstance. Our next step is to develop a simplified educational tool that uses behavioral classification in order to facilitate learning dynamic leadership during video debriefings of simulated events. By scoring leadership behavior during a simulated event and comparing it with standardized transitions in the patient's condition and needs of the performing team, residents can be taught how to adjust their behavior to the changing demand of the simulated experience. In this way, residents can develop a clearer view on whether they have developed a dynamic approach to leadership, changing their behavior depending on team experience and the task at hand, rather than sticking to the hierarchical image of the dominant, task-oriented leader.

\section{Conclusion}

Simulated emergencies provide an excellent opportunity for medical professionals to increase awareness of the influence of leadership skills in critical situations and practice leadership skills, without endangering patient safety. Results show that our pediatric residents preferentially chose a directive or coaching style to lead their team during a simulated critical event. This pattern conforms to the task- and role-related requirements in our scenarios with a transition to a critical clinical situation. The model used in this pilot study will help us to gain a better understanding of the development of leadership behavior and supports the applicability of SLT in training leadership skills during residency.

\section{Author contributions}

EHC, JMD, SH, and JLL designed and coordinated the study. SH drafted, tested, and implemented the questionnaire. JMD and JLL performed as facilitators during the simulated scenario training sessions. EHC and $\mathrm{SH}$ reviewed the video taped scenarios. EHC, SH, JMD, and JLL carried out data analysis and interpretation. EHC and SH drafted the manuscript. JMD and JLL revised it for important intellectual content. All authors read and approved the final manuscript and agree to be accountable for all aspects of the work in ensuring that questions related to the accuracy or integrity of any part of the work are appropriately investigated and resolved.

\section{Disclosure}

The authors report no conflicts of interest in this work.

\section{References}

1. Helmreich RL. On error management: lessons from aviation. BMJ. 2000;320(7237):781-785.

2. Künzle B, Kolbe M, Grote G. Ensuring patient safety through effective leadership behaviour: a literature review. Saf Sci. 2010;48:1-17.

3. Cooper S, Wakelam A. Leadership of resuscitation teams: "Lighthouse Leadership". Resuscitation. 1999;42(1):27-45.

4. Gilfoyle E, Gottesman R, Razack S. Development of a leadership skills workshop in paediatric advanced resuscitation. Med Teach. 2007;29(9):e276-e283.

5. Hersey P, Blanchard KH, LaMonica EL. A situational approach to supervision: leadership theory and the supervising nurse. Superv Nurse. 1976;7(5):17-20; 22.

6. Hersey P, Blanchard KH, Johnson DE. Management of Organizational Behavior: Utilizing Human Resources. 7th ed. Englewood Cliffs, NJ: Prentice Hall; 1996.

7. Northhouse P. Leadership: Theory and Practice. 3rd ed. Thousand Oaks CA: Sage; 2004.

8. Skog A, Peyre SE, Pozner CN, Thorndike M, Hicks G, Dellaripa PF. Assessing physician leadership styles: application of the situational leadership model to transitions in patient acuity. Teach Learn Med. 2012;24(3):225-230.

9. Horwitz IB, Horwitz SK, Daram P, Brandt ML, Brunicardi FC, Awad SS. Transformational, transactional, and passive-avoidant leadership characteristics of a surgical resident cohort: analysis using the multifactor leadership questionnaire and implications for improving surgical education curriculums. J Surg Res. 2008;148(1):49-59.

10. Cummings GG, Midodzi WK, Wong CA, Estabrooks CA. Personality and organizations: a test of the homogeneity of personality hypothesis. J Appl Psychol. 1998;83:462.

11. Hynes P, Kissoon N, Hamielec CM, Greene AM, Simone C. Dealing with aggressive behavior within the health care team: a leadership challenge. J Crit Care. 2006;21(2):224-227.

12. Cole $\mathrm{E}$, Crichton $\mathrm{N}$. The culture of a trauma team in relation to human factors. J Clin Nurs. 2006;15(10):1257-1266.

13. Smith JR, Hogg MA, Martin R, Terry DJ. Uncertainty and the influence of group norms in the attitude-behaviour relationship. BrJ Soc Psychol. 2007;46(pt 4):769-792. 
14. Itani KM, Liscum K, Brunicardi FC. Physician leadership is a new mandate in surgical training. Am J Surg. 2004;187(3):328-331.

15. Thomas JH. The surgical personality: fact or fiction. Am J Surg. 1997;174(6):573-577.
16. Hoffman BM, Coons MJ, Kuo PC. Personality differences between surgery residents, nonsurgery residents, and medical students. Surgery. 2010;148(2):187-193.

\section{Publish your work in this journal}

Advances in Medical Education and Practice is an international, peerreviewed, open access journal that aims to present and publish research on Medical Education covering medical, dental, nursing and allied health care professional education. The journal covers undergraduate education, postgraduate training and continuing medical education including emerging trends and innovative models linking education, research, and health care services. The manuscript management system is completely online and includes a very quick and fair peer-review system. Visit http://www.dovepress.com/testimonials.php to read real quotes from published authors.

Submit your manuscript here: http://www.dovepress.com/advances-in-medical-education-and-practice-journal 